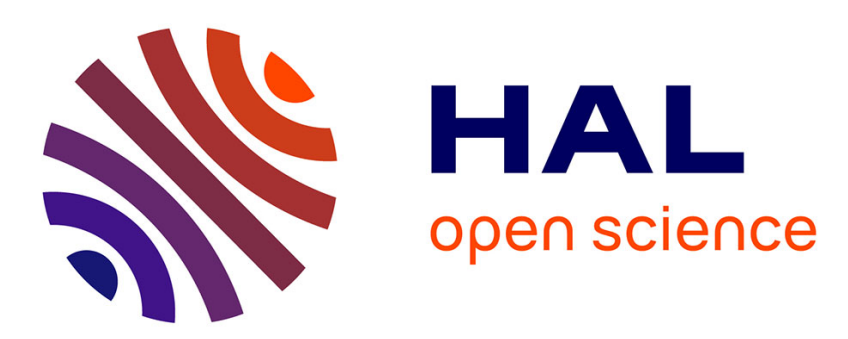

\title{
Study on the Temporal and Spatial Variability of Maize Yield in Precision Operation Area
}

\author{
Yueling Zhao, Haiyan Han, Liying Cao, Li Ma, Guifen Chen
}

\section{To cite this version:}

Yueling Zhao, Haiyan Han, Liying Cao, Li Ma, Guifen Chen. Study on the Temporal and Spatial Variability of Maize Yield in Precision Operation Area. 8th International Conference on Computer and Computing Technologies in Agriculture (CCTA), Sep 2014, Beijing, China. pp.714-719, 10.1007/9783-319-19620-6_77 . hal-01420288

\section{HAL Id: hal-01420288 \\ https://hal.inria.fr/hal-01420288}

Submitted on 20 Dec 2016

HAL is a multi-disciplinary open access archive for the deposit and dissemination of scientific research documents, whether they are published or not. The documents may come from teaching and research institutions in France or abroad, or from public or private research centers.
L'archive ouverte pluridisciplinaire HAL, est destinée au dépôt et à la diffusion de documents scientifiques de niveau recherche, publiés ou non, émanant des établissements d'enseignement et de recherche français ou étrangers, des laboratoires publics ou privés. 


\title{
Study on the temporal and spatial variability of maize yield in precision operation area
}

\author{
Yueling Zhao ${ }^{1}$, Haiyan $\mathrm{Han}^{2}$, Liying $\mathrm{Cao}^{1}$, Li MA ${ }^{1}$, Guifen Chen*1 \\ 1 Jilin agricultural university , Jilin 130118; 2 Changchun university, Jilin 130000,
}

\begin{abstract}
Jilin province is an important agricultural production resource in our country. Study on the temporal and spatial variability of maize yield are significant to understand the potential nutrients in soil, and guide agricultural practice for the recent years in precision operate area. The every year yield distribution belonged to the normal distribution by testing K-Sand the coefficient of variation of them were $16.33 \%, 11.85 \%, 12.90 \%$ respectively. That precise operation can reduce the yield difference in every operate cell. As a result, the temporal and spatial variability of maize yield can be successfully applied to yield prediction in Jilin Province. Partition results can not only guide soil nutrient evaluation, and can be used to implement variable input and precise fertilization recommendation.
\end{abstract}

Key Words: temporal and spatial variability, maize yield, precision agriculture

\section{INTRODUCTION}

It is directly affect agricultural production regenerative potential, that yield prediction status are understood, so the maize yield level of the comprehensive analysis and evaluation is very necessary, it is the use of agricultural resources and technology in an effective way. In precision fertilization can be employed in management zones instead of grid sampling technology, and the extensive application ${ }^{[1-3]}$. In recent years, with the precision production technology system improvement and application in our country, some researcher used crop yield data of many years in comprehensive analysis in agricultural management partition extraction research.

With the precise operation technology in agricultural production in China continues to expand and application of crop production, continuously improved, the maize problem is getting more and more attention under the background, how to predict the future of food production for a period of time has become a research hotspot ${ }^{[4]}$. To investigate the relationship between the precision maize yield and time series, and the results of the comprehensive analysis and study is very necessary, it is a way of effective use of agricultural resources and technology. Through the analysis of precision for variation characteristics of maize yield, on the one hand can be scientific, reasonable, effective evaluation on it, on the other hand, the workers engaged in agricultural production not only can improve the use efficiency of soil nutrients, but also save the resources, obtain better economic benefits, to protect the ecological agriculture resources and the quality of environment. The temporal and spatial variability of maize yield were studied for some years in precision area in the paper.

\section{MATERIALS AND METHODS}

\section{1 the Situation of the Study Area}

The study area is located in yushu City of Jilin Province. The researcher area was located at latitude 44.999369 45.002761, longitude $126.3139-126.31671$. The genus sub-humid temperate continental monsoon climate, annual average temperature is $4.6{ }^{\circ} \mathrm{C}-5.6{ }^{\circ} \mathrm{C}$, annual precipitation is the middle of in $500-600 \mathrm{~mm}$, and the accounting for $90 \%$ of annual rainfall is concentrated in the warm season, the soil is more fertile, soil types are suitable for planting maize, bean, rice and other various crops. The distribution map of soil samples can be shown from the Fig.1.

*Corresponding author E-mail: zyueling@163.com 


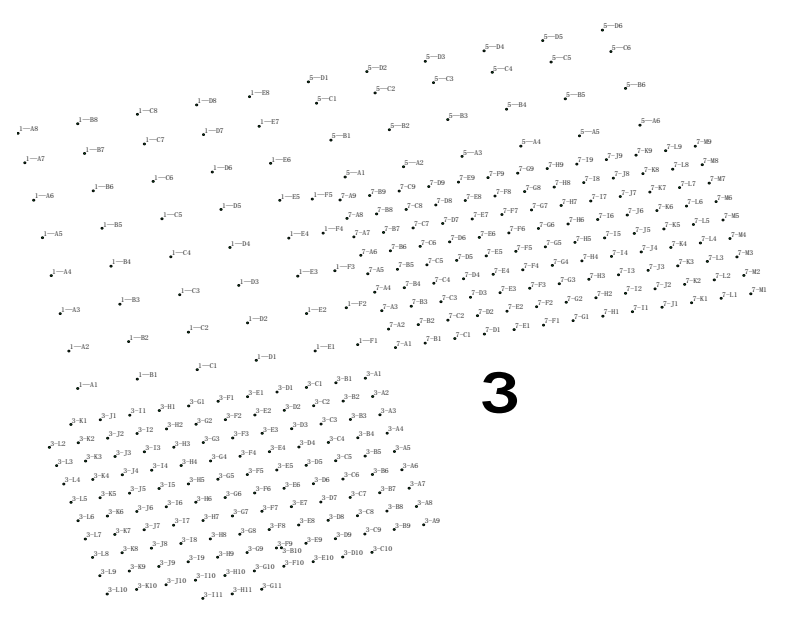

Fig.1 distribution map of soil samples

\subsection{Process and Methods}

We used DGPS(Differential Global Satellite Positioning System) devices in USA company Trimble for accurate positioning, set point, draw the boundary line and on the acquisition of land area. Then the researchers are back to the lab with the data by using ArcGIS software to the plots of the data collected by the spacing is according to $40 \mathrm{~m} * 40 \mathrm{~m}$ as a unit area of the anchor point, classification, determination sampling points and sampling points map making. The actual measured area of a sample, the number of samples of corn plants, rough calculation can count per plant grain number per unit area yield of maize, the calculation according to the following formula: 1000 grain weight (grams) $* \mathrm{Mu} *$ panicle number $/ 1000000=$ $\mathrm{kg} / \mathrm{mu}$, and the yield of unit conversion into kg.ha ${ }^{-1}$. The results can be shown from Tab.1

\subsection{Data Analysis}

All the experimental data were analysed using SPSS 18.0 and ArcGIS as tools in the processing. At first, the samples data were standardized, then in order to achieve data sharing, the maize yield results are be saved to the excel table and input to the precision agricultural database.

A quantitative tool of geostatistics as a soil variable space analysis, can be analysed by variation function, discrimination, contrast observation data, it is used to describe the spatial difference between the variables of the form of function, it is a kind of distance measure function $\mathrm{H}$. It describes the similarity between the two sampling points, the similarity decreases as the distance between sampling points. When the distance between them to a certain extent, they often have no correlation, this time they will become two independent. It is a tool to describe the function of the spatial variability of soil properties in different distance between observation and reflect the changes of values, so the half of the definition of semi variance function to describe the variance the difference between the two sampling points, the formula is as follows ${ }^{[5-6]}$ :

$$
\gamma(h)=\frac{1}{2 N(h)} \sum_{i=1}^{N(h)}\left[z\left(x_{i}+h\right)-z\left(x_{i}\right)\right]^{2}
$$

In the formula, $h$ is the space distance of the sample points, also known as step or potential difference (Lag); $N(h)$ represents the spatial isolation distance apart as the number of samples $h$. The value of $Z\left(X_{i}\right)$ and $Z\left(x_{i}+h\right)$ were measured in two position. $\gamma(\mathrm{h})$ is the value of the semi-variance function. Variation as a function of distance is the semi variance of $\mathrm{H}$, and increases with the increase of $\mathrm{H}$ in the semi variance function within a certain range, but when the maximum distance between the observation point is greater than the distance between the regional variables, the values of the function tends to a constant, and contains steady state. 
Tab.1 The measured data of output in 2004

\begin{tabular}{|c|c|c|c|c|c|c|c|}
\hline NO. & LON & LAN & $\begin{array}{c}\text { Yield } \\
\left(\mathrm{kg} \cdot \mathrm{ha}^{-1}\right)\end{array}$ & NO. & LON & LAN & $\begin{array}{c}\text { Yield } \\
\left(\mathrm{kg} \cdot \mathrm{ha}^{-1}\right)\end{array}$ \\
\hline $3-\mathrm{A} 1$ & 126.31574 & 45.002761 & 7812.4 & $3-\mathrm{C} 8$ & 126.31573 & 44.999805 & 7869.4 \\
\hline $3-\mathrm{A} 2$ & 126.31586 & 45.002414 & 7354.1 & 3-C9 & 126.31585 & 44.999458 & 8077.2 \\
\hline $3-\mathrm{A} 3$ & 126.31598 & 45.002066 & 7561.8 & $3-\mathrm{C} 10$ & 126.31427 & 45.002498 & 8102.7 \\
\hline 3-A4 & 126.3161 & 45.001718 & 6921.5 & 3-D1 & 126.31439 & 45.00215 & 7589.6 \\
\hline 3-A5 & 126.31623 & 45.001371 & 6219.5 & 3-D2 & 126.31451 & 45.001803 & 7687.5 \\
\hline $3-\mathrm{A} 6$ & 126.31635 & 45.001023 & 6423.7 & 3-D3 & 126.31463 & 45.001455 & 6986.4 \\
\hline 3-A7 & 126.31647 & 45.000676 & 6635.4 & 3-D4 & 126.31475 & 45.001107 & 7152.8 \\
\hline $3-\mathrm{A} 8$ & 126.31659 & 45.000328 & 7324.1 & 3-D5 & 126.31488 & 45.00076 & 7354.6 \\
\hline 3-A9 & 126.31671 & 44.99998 & 6523.7 & $\ldots$ & $\ldots$ & & 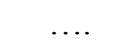 \\
\hline $3-\mathrm{A} 10$ & 126.31525 & 45.002674 & 6952.2 & $3-\mathrm{K} 3$ & 126.31242 & 44.998843 & 9482.7 \\
\hline 3-A1 & 126.31574 & 45.002761 & 7812.4 & $3-\mathrm{K} 4$ & 126.31083 & 45.001884 & 8897.7 \\
\hline \multirow[t]{2}{*}{$3-\mathrm{A} 2$} & 126.31586 & 45.002414 & 7354.1 & $3-\mathrm{K} 5$ & 126.31095 & 45.001536 & 8046.2 \\
\hline & & & & 3-K6 & 126.31107 & 45.001188 & 8157.9 \\
\hline $3-\mathrm{C} 7$ & 126.31561 & 45.000152 & 8260.6 & $3-\mathrm{K} 7$ & 126.31119 & 45.000841 & 7982.5 \\
\hline $3-\mathrm{C} 8$ & 126.31573 & 44.999805 & 7869.4 & $3-K 8$ & 126.31132 & 45.000493 & 8534.6 \\
\hline
\end{tabular}

\section{RESULTS AND ANALYSIS}

\section{1 the Descriptive Statistics of Soil Nutrient Data}

In the study of soil science, the magnitude coefficient of variation (CV) usually represented spatial variability strength of soil nutrient characteristics . It is usually weak variability if variation coefficient of $\mathrm{CV} \leq 0.1,0.1<\mathrm{CV}<1$ as moderate variability, $C V \geq 1$ strong variability ${ }^{[7-8]}$. Study on the variation characteristics of maize yield is each are not identical, soil of different yield properties have bigger difference.

Table 2 Attribute characteristics in different years of production

\begin{tabular}{ccccccccc}
\hline Case & Mean & SD & Variance & Kurtosis & CV\% & Min & Max & K - S \\
\hline 2004 & 8422.668 & 1375.178 & 0.605 & 0.31 & 16.33 & 6005.8 & 12328.2 & 0.702 \\
2007 & 9069.098 & 1170.657 & -0.3 & -1.02 & 12.9 & 6606.4 & 10986.4 & 0.139 \\
2009 & 7303.635 & 865.239 & 0.105 & 0.33 & 11.85 & 5182.23 & 9765.11 & 0.966 \\
\hline
\end{tabular}

The cell yield of these three years by K-S test, its distribution accords with the normal distribution, The average maize yield is the mean $8422.67 \mathrm{~kg}$.ha-1 in 2004, the average maize yield is average $9069.1 \mathrm{~kg}$.ha- 1 in 2007 , the average maize yield is 7303.63 kg.ha-1in 2009 from the table 2.The coefficient of variation of them were 16.33\%, 11.85\%, 12.90\%, coefficient of variation, as can be shown in Figure 2.The yield decreased gradually, and engaged in precision during the operation, the coefficients of variation were less than $20 \%$, belongs to the medium variation. 


\section{2 the temporal and spatial variability of maize yield}

Observation of 2004 to yield spatial distribution map of 5-14 in 2009 2004, can be seen in the cell changes in output frequency is larger, and with the precision of the year by year, change of output frequency in cells decreased obviously, the first two years of the analysis of production trends can be seen, the east-west direction on the production line is steeper, after several wheel precise operation, each cell analysis of the yield curve changes in the east-west direction, they yield trend line close to the line is smooth, it also shows that the spatial variation of yield decreased, difference in. That precise operation can reduce the yield difference within a cell.

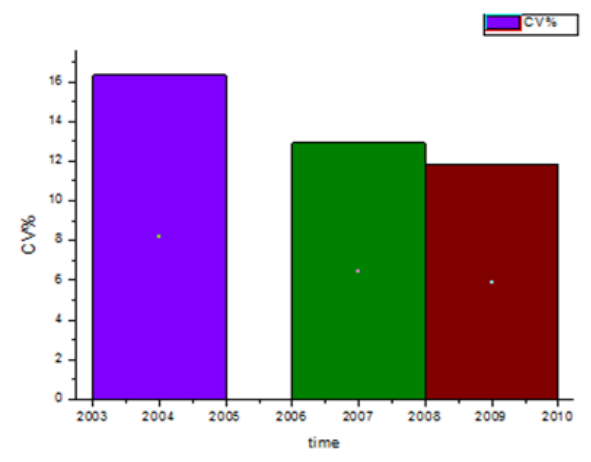

Fig. 2 Three years of variation coefficient of yield comparison chart
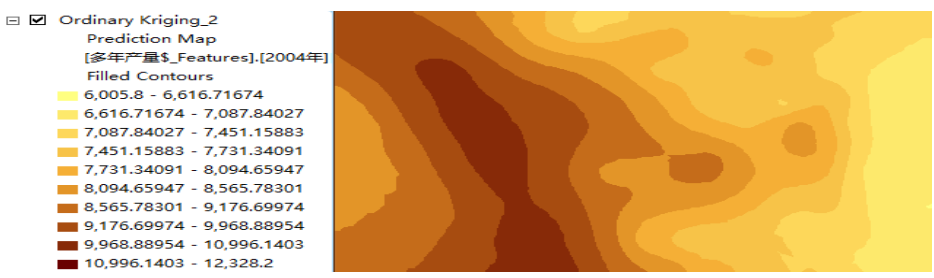

Fig.3 The spatial attribute graph of output in 2004

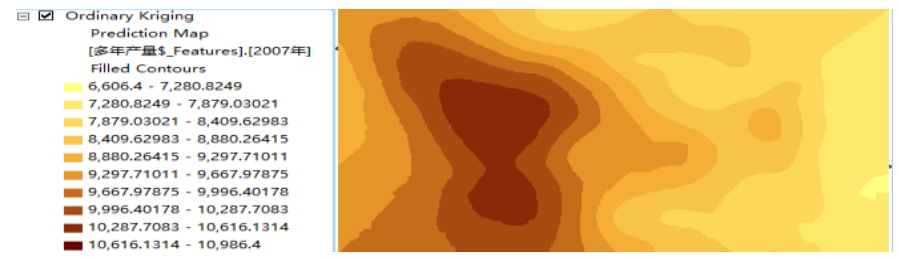

Fig.4 The spatial attribute graph of output in 2007

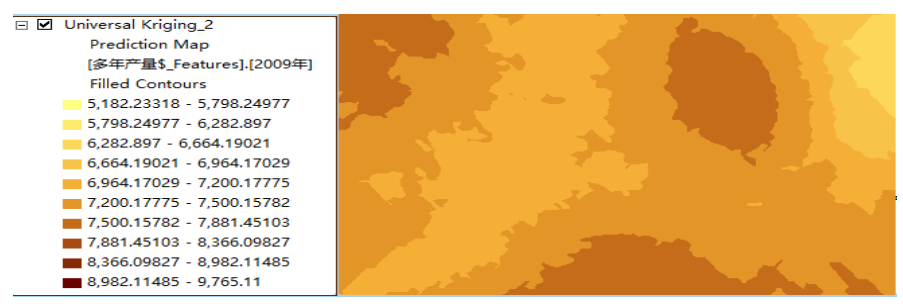

Fig.5 The spatial attribute map of output in 2009 


\section{RESULTS AND DISCUSSION}

In the actual process of agricultural production, researchers know Soil Nutrient timing variability exists, don't also aware of the crop yield in the study area also exists obvious spatio-temporal variation. The application of traditional time the total output of grain in Shandong province of the prediction model and the ARIMA model predicts that the regression equation by Zhang Xiaojie et al. The prediction effect is relatively good ${ }^{[9]}$. Of course, the variability of maize yield is affected by many factors, such as variety, environment, climate, plant diseases and insect pests, cultivation mode and management mode, through the analysis of precision operation area in recent years, soil nutrient and yield data, mining and grasp the changes of crop yield in space and time, the characteristic of temporal variation of maize yield was given in recent years.

\section{ACKNOWLEDGMENTS}

This work is supported by the Jilin province education science planning projects (Grant No. GH13180) ; Jilin Agricultural University general topic (Grant No. 2012xjyb048); department of education of Jilin Province (Grant No. 2013(68) ); Science and TechnologyBureau of Changchun city ( Grant No. 13KG71 ). The authors also gratefully acknowledge the helpful comments and suggestions of the reviewers, which have improved the presentation.

\section{References and Notes}

1. Zhang Hua, Zhang Gan Lin. Farm scale spatial variability of soil quality indicators. Chinese Journal of Soil Science, 34(4):241-245, (2003).

2. Schepers A R, Shanahan J F, Liebig M K, Schepers J S, Johnson S H, Jr A L. Appropriateness of management zones for characterzing spatial variability of soil properties and irrigated corn yields across years. Agronomy Journal, 96:195203.(2004).

3. Wu xiao-lei, Wang da-qing, Xu bo, et al. Spatial Variability of Black soil Nutrients in Hilly Land Chinese journal of Soil Science 41(4):825-829, (2010).

4. Heidy Sanchez Lizarraga, Carlo G. Lai.Effects of spatial variability of soil properties on the seismic response of an embankment dam.Soil Dynamics and Earthquake Engineering, 2014,64(9), 113-128

5.Tiejun Wang, Trenton E. Franz, Vitaly A. Zlotnik,et al. Investigating soil controls on soil moisture spatial variability: numerical simulations and field observations Journal of Hydrology[J].Accepted Manuscript, Available online 16 March 2015

6.Miriam Glendell, Steve J. Granger, Roland Bol, et al. Quantifying the spatial variability of soil physical and chemical properties in relation to mitigation of diffuse water pollution[J].Geoderma, 2014, 214-215(2), 25-41.

7.C. Narendra Babu, B. Eswara Reddy .A moving-average filter based hybrid ARIMA-ANN model for forecasting time series dataOriginal Research Article Applied Soft Computing, 2014, 23(10):27-38

8. George C. Tiao Time Series: ARIMA Methods International Encyclopedia of the Social \& Behavioral Sciences (Second Edition), 2015, 316-321

9. Zhan xiao jie, Zhang ziliang .Application of time series analysis model on total corn yield of Shandong province [J]. Research of water conservation, 2007,14(3):309-311. 